\title{
Comprehensive Genetic Analysis of OEIS Complex Reveals No Evidence for a Recurrent Microdeletion or Duplication
}

\author{
Christopher N. Vlangos, ${ }^{1,2}$ Amanda Siuniak, ${ }^{1,2}$ Todd Ackley, ${ }^{1}$ Hans van Bokhoven, ${ }^{3}$ Joris Veltman, ${ }^{3}$ \\ Ram lyer, ${ }^{1,4}$ John M. Park, ${ }^{5}$ Kim Keppler-Noreuil, ${ }^{6}$ and Catherine E. Keegan ${ }^{1,2 *}$ \\ ${ }^{1}$ Department of Pediatrics, University of Michigan, Ann Arbor, Michigan \\ ${ }^{2}$ Department of Human Genetics, University of Michigan, Ann Arbor, Michigan \\ ${ }^{3}$ Department of Human Genetics, Nijmegen Centre for Molecular Life Sciences, Radboud University Nijmegen Medical Center, Nijmegen, \\ The Netherlands \\ ${ }^{4}$ Department of Pathology, University of Michigan, Ann Arbor, Michigan \\ ${ }^{5}$ Department of Urology, University of Michigan, Ann Arbor, Michigan \\ ${ }^{6}$ Department of Pediatrics/Division of Medical Genetics, University of lowa Hospital \& Clinics, lowa City, lowa
}

Received 30 April 2010; Accepted 13 September 2010

Omphalocele-exstrophy of the bladder-imperforate anus-spinal defects (OEIS) complex, or cloacal exstrophy (EC), is a rare constellation of malformations in humans involving the urogenital, gastrointestinal, and skeletal systems, and less commonly the central nervous system. Although OEIS complex is wellrecognized in the clinical setting, there remains a significant lack of understanding of this condition at both the developmental and the genetic level. While most cases are sporadic, familial cases have been reported, suggesting that one or more specific genes may play a significant role in this condition. Several developmental mechanisms have been proposed to explain the etiology of OEIS complex, and it is generally considered to be a defect early in caudal mesoderm development and ventral body wall closure. The goal of this study was to identify genetic aberrations in 13 patients with OEIS/EC using a combination of candidate gene analysis and microarray studies. Analysis of 14 candidate genes in combination with either high resolution SNP or oligonucleotide microarray did not reveal any disease-causing mutations, although novel variants were identified in five patients. To our knowledge, this is the most comprehensive genetic analysis of patients with OEIS complex to date. We conclude that OEIS is a complex disorder from an etiological perspective, likely involving a combination of genetic and environmental predispositions. Based on our data, OEIS complex is unlikely to be caused by a recurrent chromosomal aberration. ๑ 2010 Wiley-Liss, Inc.

Key words: omphalocele-exstrophy of the bladder-imperforate anus-spinal defects (OEIS) complex; cloacal exstrophy; candidate gene analysis; array CGH

\section{INTRODUCTION}

Omphalocele-exstrophy of the bladder-imperforate anus-spinal defects (OEIS) complex or cloacal exstrophy (EC), is a rare con-
How to Cite this Article:

Vlangos CN, Siuniak A, Ackley T, van

Bokhoven H, Veltman J, Ram Iyer, Park JM,

Keppler-Noreuil K, Keegan CE. 2011.

Comprehensive genetic analysis of OEIS

complex reveals no evidence for a recurrent

microdeletion or duplication.

Am J Med Genet Part A 155:38-49.

stellation of malformations involving multiple organ systems in humans [Carey et al., 1978; Kallen et al., 2000; Keppler-Noreuil, 2001; Martinez-Frias et al., 2001]. The incidence of OEIS complex is estimated to be 1 in 200,000 live births although this may be an underestimate of the total number of cases because it lacks inclusion of stillbirths and pregnancy terminations [Martinez-Frias et al., 2001; Keppler-Noreuil et al., 2007]. Nevertheless, individuals born with this malformation complex require immediate

Additional supporting information may be found in the online version of this article.

Grant sponsor: University of Michigan Department of Pediatrics AmendtHeller Award for Newborn Research and Rackham Faculty Research Grant. ${ }^{\star}$ Correspondence to:

Catherine E. Keegan, M.D., Ph.D., 1150 W. Medical Center Dr., 3520C MSRB I, Box 5652, Ann Arbor, MI 48109-5652.

E-mail: keeganc@med.umich.edu

Published online 22 December 2010 in Wiley Online Library

(wileyonlinelibrary.com).

DOI 10.1002/ajmg.a.33757 
surgical intervention and suffer from significant long-term disabilities.

The pathophysiology of OEIS complex is unknown. OEIS/EC is hypothesized to be part of a spectrum of malformations, also known as BEEC, which includes bladder exstrophy (BE) and epispadias. Several hypotheses have been proposed to explain the developmental mechanisms leading to the phenotypic expression of OEIS complex and BE [Keppler-Noreuil, 2001; Martinez-Frias et al., 2001; Bohring, 2002; Siebert et al., 2005; Sadler and Feldkamp, 2008; Ludwig et al., 2009a]. OEIS complex is thought to be caused by a defect in caudal mesoderm formation and migration between the ectodermal and endodermal layers of the cloacal membrane, leading to premature or abnormal rupture of the cloacal membrane. The phenotype of OEIS complex versus $\mathrm{BE}$ is hypothesized to be due to the timing of abnormal cloacal membrane rupture with respect to migration of the urorectal septum [Jones, 1997; Keppler-Noreuil, 2001]. More recently, it has been proposed that OEIS/EC is due to failure in closure of the ventral body wall, which occurs during the third and fourth weeks of development [Sadler and Feldkamp, 2008]. Limb-body wall complex (LBWC) and urorectal septum malformation sequence (URSMS) also share overlapping features with OEIS/EC, and it has been hypothesized that they also share an underlying etiology [Heyroth-Griffis et al., 2007]. Other malformations of the caudal portion of the embryo share some features with OEIS complex, including vertebral-anal -cardiac-tracheoesophageal fistula-renal-limb (VACTERL) association and caudal regression syndrome (CRS) [Bohring, 2002; Siebert et al., 2005]. All of these conditions have an unknown etiology.

Most cases of OEIS complex are sporadic. However, reports of familial cases and higher rates of concordance in monozygotic twins provide support for a genetic etiology [Lee et al., 1999; KepplerNoreuil, 2001; Boyadjiev et al., 2004]. Although rare chromosomal anomalies have been reported and a few candidate genes have been analyzed in small numbers of patients [Nye et al., 2000; Boyadjiev et al., 2004, 2005; Reutter et al., 2006; Kruger et al., 2008; El-Hattab et al., 2010], no causative genes have been identified. Environmental influences have also been proposed, although no clear environmental predisposition has emerged from epidemiological studies [Kallen et al., 2000; Martinez-Frias et al., 2001; Boyadjiev et al., 2004; Keppler-Noreuil et al., 2007].

Here, we report on a genetic analysis of 13 individuals with OEIS complex. For this analysis we considered that it was important to analyze only OEIS cases and not isolated BE. To identify pathogenic copy number variations (CNVs) that might be responsible for the OEIS phenotype, we performed high resolution SNP and oligonucleotide microarrays on our patient cohort. We also sequenced 14 candidate genes that were predicted to cause an OEIS complex phenotype in humans based on caudal and/or urogenital defects in humans or in mouse models and/or expression patterns. Although no pathogenic mutations were identified in our patient sample, this is the most comprehensive genetic analysis of patients with OEIS complex to date. Based on our data, we can conclude that OEIS complex is unlikely to be caused by a recurrent chromosomal microdeletion or duplication.

\section{MATERIALS AND METHODS}

\section{Experimental Subjects}

Written informed consent was obtained from all study participants in accordance with approved protocols from the Institutional Review Board of the University of Michigan. Clinical features of the 13 patients included in this study are shown in Table I. All patients had at least two of the cardinal features of OEIS complex, with the majority having all four cardinal features. One sample (Patient 19) was from a fetus with the characteristic ultrasound findings of OEIS complex. DNA was isolated from blood or buccal samples using the Gentra Puregene DNA isolation kit (QiagenUSA, Valencia, CA) per manufacturer instructions. Buccal DNA samples were obtained only from parents for confirmatory testing.

\section{PCR and DNA Sequencing of Candidate Genes}

PCR was performed in $20 \mu \mathrm{l}$ reaction volumes containing $1 \mu \mathrm{M}$ forward and reverse primers and $1 \times$ Taq-Pro Complete (Denville Scientific, Metuchen, NJ). PCR cycling was performed in an Eppendorf Mastercycler (Eppendorf North America, Westbury, $\mathrm{NY}$ ) with conditions as follows: initial denature $95^{\circ} \mathrm{C}$ for $15 \mathrm{~min}, 25$ cycles $95^{\circ} \mathrm{C}$ for $30 \mathrm{sec}, 72^{\circ} \mathrm{C}-0.7^{\circ} \mathrm{C} /$ cycle for $30 \mathrm{sec}, 72^{\circ} \mathrm{C}$ for $1 \mathrm{~min}$, 21 cycles $95^{\circ} \mathrm{C}$ for $30 \mathrm{sec}, 55^{\circ} \mathrm{C}$ for $30 \mathrm{sec}, 72^{\circ} \mathrm{C}$ for $1 \mathrm{~min}$, followed by a single $72^{\circ} \mathrm{C}$ extension for $10 \mathrm{~min}$. PCR primer sequences are available by contacting the corresponding author. PCR results were analyzed on $1 \%$ agarose gels electrophoresed in $1 \times$ Tris-acetate buffer. PCR products were purified using Qiagen PCR purification columns (Qiagen-USA) and sequenced by the University of Michigan DNA sequencing core. Sequence analysis was performed by aligning patient DNA sequences to the human genome consensus sequence (hg18/build 36, released March 2006 as viewed at http:// www.genome.ucsc.edu) using the Sequencher computer program (GeneCodes, Ann Arbor, MI). All DNA changes identified were compared to known polymorphisms located in dbSNP (http:// www.ncbi.nlm.nih.gov/projects/SNP/). Changes identified as novel were tested in parental DNA samples when available.

\section{Mutation Analysis of the MT-RNR1 Gene}

Mutation screening of the mitochondrial chromosome at position 1555 within the $M T-R N R 1$ gene was performed by PCR and RFLP analysis as previously described [Nye et al., 2000].

\section{TaqMan Assays}

TaqMan DNA copy number assays were performed on an ABI7500 Real-Time PCR System (Applied Biosystems, Foster City, CA). Reactions were performed in $25 \mu$ volumes containing $1 \times$ FAMlabeled locus specific TaqMan gene copy assay, $1 \times$ VIC-labeled $R$ Nase $P$ copy number reference assay, $1 \times$ TaqMan gene expression master mix, and $40 \mathrm{ng}$ template DNA. Cycling conditions were hold/denature $95^{\circ} \mathrm{C}$ for $10 \mathrm{~min}$, followed by 40 cycles of $95^{\circ} \mathrm{C}$ for $15 \mathrm{sec}, 60^{\circ} \mathrm{C}$ for $60 \mathrm{sec}$. The manual $\mathrm{C}_{\mathrm{T}}$ threshold of the $\mathrm{ABI} 7500$ was set to 0.2 , and the autobaseline was on. Taqman assay Hs04956436_ cn representing the CHN2 gene and assay Hs00345272_cn representing the $A N K Y F 1$ gene were used for patients number 1 and 


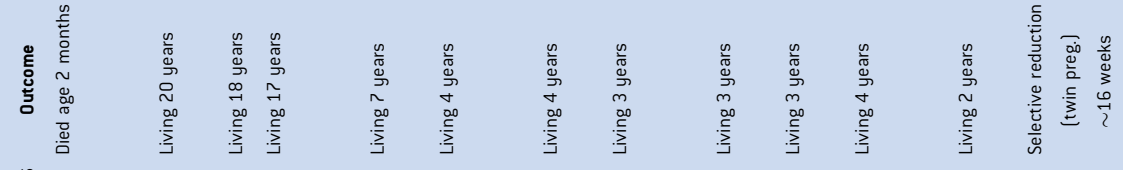

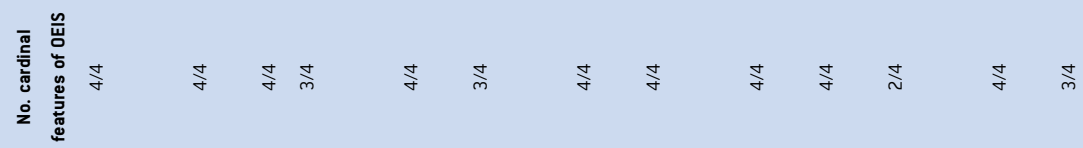

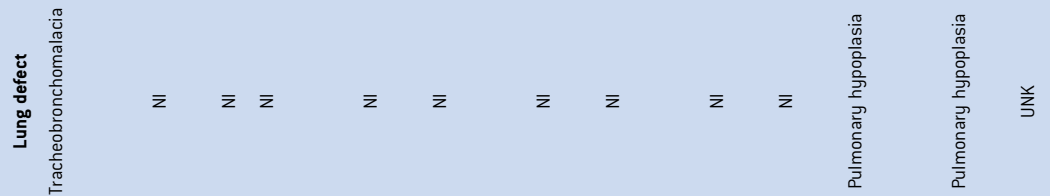

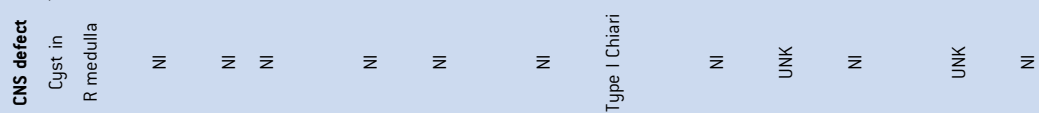

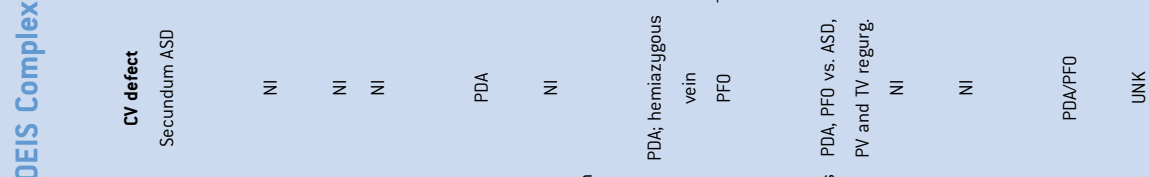

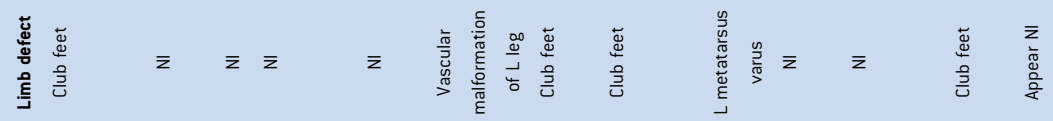

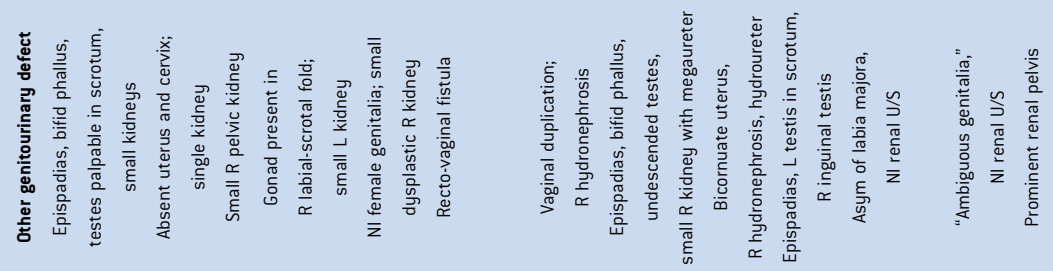

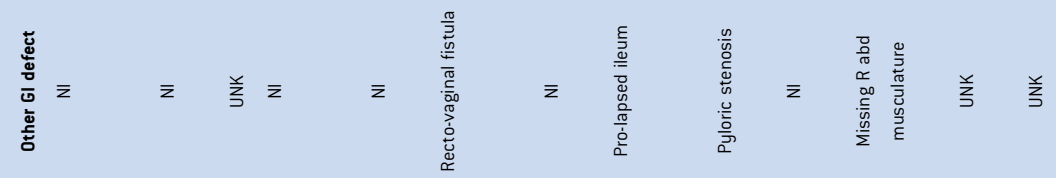







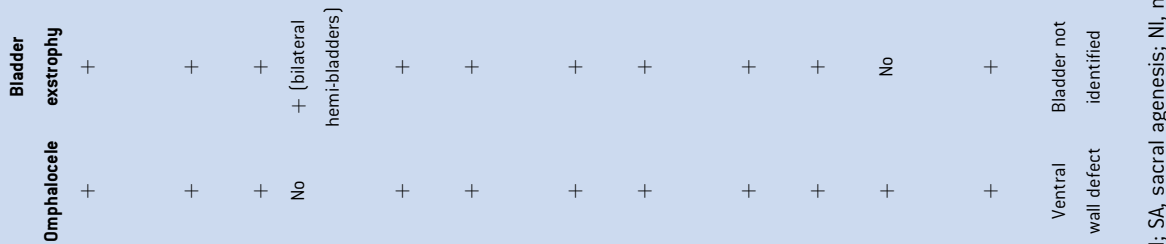




number 9 respectively. A control assay (Hs05018555_cn) was also performed to detect a deletion carried by patient 11 mapping to chromosome 7p21.3. All reactions were performed at least two times in triplicate. DNA copy number was calculated using Applied Biosystem's CopyCaller software version 1.0 comparing locus specific copy number to the RNase P control.

\section{SNP Chip Analysis}

DNA for microarray analysis was purified over a QIAamp spin column (Qiagen, QIAGEN Benelux B.V., KJ Venlo, the Netherlands) followed by digestion with NspI. Specific adaptors were ligated and fragments of 200-1,000 bp were amplified via optimized PCR conditions. The amplified DNA was then fragmented, labeled, and hybridized to a GeneChip Mapping 250K SNP Array (Affymetrix, Santa Clara, CA). The 250K SNP microarray was run on the GeneChip Scannner 3000 7G with autoloader, GeneChip Fluidics station 450, and GeneChip Hybridisaton oven 640 (Affymetrix).

The 250K SNP data were analyzed with GeneChip Genotyping Analysis Software (GTYPE, Affymetrix), which uses an automated, model-based genotype-calling algorithm that provides a confidence score for each individual genotype. Copy number estimates were determined automatically using the CNAG 2.0 software package by a hidden markov model [Nannya et al., 2005]. Microdeletions and duplications detected by SNP microarray analysis were first compared to an in-house reference dataset of patients with disorders other than OEIS complex as well as to the Database of Genomic Variants (http://projects.tag.ca/variation). Copy number changes that occur as non-pathogenic variants in the human genome were excluded from further analysis.

\section{Oligo Array Analysis}

In separate tubes, $1,010 \mathrm{ng}$ of patient genomic DNA and of sexmismatched pooled reference genomic DNA were double-digested with the restriction enzymes AluI and RsaI (Promega, Madison,
WA) and then fluorescently labeled with Cy3 and Cy5 respectively, using the Genomic DNA Labeling Kit Plus (Agilent Technologies, Santa Clara, CA). Labeled DNA samples were cleaned up of reagents and unincorporated dyes by vacuum filtration using the MultiScreen HTS Filtration plates (Millipore, Billerica, MA) and resuspended in $22 \mu \mathrm{l}$ of $1 \times$ tris-EDTA. Purified fluorescently labeled patient and reference DNAs were mixed together, and hybridized to an Agilent $244 \mathrm{~K}$ oligonucleotide array using standard reagents and protocols supplied by the array manufacturer (Agilent Technologies). Arrays were hybridized for $40 \pm 4 \mathrm{hr}$, and washed using Agilent wash procedure B.

Arrays were scanned on a GenePix 4200A scanner (Molecular Devices, Sunnyvale, CA), enclosed in a NoZone ${ }^{\circledR}$ TL Workspace, using GenePix Pro 6.1 software. Gains and losses were called according to interpretation criteria established by the International Standard Cytogenomic Array (ISCA) Consortium, as described in Baldwin et al. [2008]. The resulting $\log 2$ derivatives of the patient/ control signal intensity ratios were plotted relative to the genomic location of the corresponding probes. For detection of gains or losses the thresholds for the $\log 2$ ratios were set at -0.32 for losses and 0.26 for gains. A minimum of 4 contiguous oligonucleotide probes showing loss or gain of signal intensity is needed to make an aberration call.

\section{RESULTS \\ SNP Chip Analysis}

Affymetrix $250 \mathrm{~K}$ SNP arrays were run on seven patient samples from our cohort. DNA gains and/or losses were detected in four patient samples tested, and a total of 11 different changes were identified (Table II). Ten of the changes were unique, while one occurred in three of the seven samples tested. The recurrent change is a duplication mapping to chromosome 17q21.31 covering bases 41,521,621-41,647,903 (March 2006 human genome build (hg18) as displayed on the UCSC Genome Browser). The DNA that is duplicated in our patients flanks a known disease locus. Deletion

TABLE II. Copy Number Variation Identified by SNP Array

\begin{tabular}{|c|c|c|c|c|}
\hline Patient & Chromosome band & Location & Type & Change \\
\hline \multirow[t]{2}{*}{$\# 1$} & 7p15.1 & 29165987-29510059 & Gain & +1 \\
\hline & $17 q 21.31-q 21.32$ & $41513416-42150418$ & Gain & +1 \\
\hline \multirow[t]{5}{*}{ \#2 } & $5 q 21.1$ & $101110353-101122504$ & Gain & +1 \\
\hline & $11 \mathrm{p} 15.1$ & 18907033-18918255 & Gain & +1 \\
\hline & $17 q 21.31-q 21.32$ & 41521621-41647903 & Gain & +1 \\
\hline & $22 q 11.1$ & 15268818-15659603 & Gain & +1 \\
\hline & Xp22.31 & 7355904-7413831 & Loss & -1 \\
\hline \multirow[t]{4}{*}{ \#9 } & $17 p 13.2$ & $3945948-4270085$ & Gain & +1 \\
\hline & $18 q 12.1$ & $27230880-27295732$ & Gain & +1 \\
\hline & $4 p 15.31$ & 18595704-18733330 & Loss & -1 \\
\hline & $6 q 21$ & 110348917-110400167 & Loss & -1 \\
\hline \multirow[t]{2}{*}{ \#11 } & 7p21.3 & $8735273-8961255$ & Loss & -1 \\
\hline & $17 q 21.31-q 21.32$ & $41474846-41707>06$ & Gain & +1 \\
\hline
\end{tabular}


of the MAPT locus on chromosome $17 \mathrm{q} 21.31$ is a known cause of a syndrome characterized by mental retardation and dysmorphic features [Koolen et al., 2006]. However, the region we identified as duplicated in our patient cohort is distal to this known genomic disorder, is reported to be extremely polymorphic for copy number, and is well represented in the database of genomic variants. Of the ten remaining regions, six were present in the database of genome variants and were not investigated further. Two regions identified were not found in the database of genomic variants, but did not contain any genes, and were not identified in more than one patient sample.

In two patient samples we identified changes not completely represented in the database of genomic variants, each containing coding DNA sequences. Patient 1 carries a $344 \mathrm{~kb}$ pair duplication of chromosome 7p15.1 spanning bases 29,165,987-29,510,059 (Fig. 1A,C). The duplication contains the beta chimerin gene (CHN2; GenBank Accession: NM_004067). The proximal breakpoint of this duplication maps within intron 9 of the CHN2 gene and as such could result in functional monosomy of the gene if the duplicated region is inverted or could result in a dominant negative allele if the duplicated region is in tandem. In patient 9 we identified a $324 \mathrm{~kb}$ pair duplication of chromosome 17p13.2 spanning bases
3,945,948-4,270,085 containing four genes (Fig. 1B,D). Three of the genes are wholly duplicated resulting in trisomy; cytochrome b5 domain containing 2 (CB5D2; GenBank Accession: NM_144611), ankyrin repeat and FYVE domain containing 1 ( $A N K F Y$ 1; GenBank Accession NM_016376), and ubiquitin-conjugation enzyme E2G 1 (UBE2G1; GenBank Accession: NM_003342). A fourth gene, zinc finger ZZ-type and EF hand domain containing protein 1 (ZZEF1; GenBank Accession NM_015113) spans the distal breakpoint of the duplication. Both of these novel regions were further studied using Taqman assays in order to validate the data and test parental DNA to determine segregation.

\section{Oligo Array Analysis}

244K Agilent oligo array assays were performed on seven patients from our cohort; the sample from Patient 11 was assayed with both the Affymetrix SNP and Agilent oligo arrays. Both genomic aberrations carried by Patient 11 identified by SNP analysis were confirmed by the oligo array. In addition, the oligo array identified 11 additional copy number variations in the sample from Patient 11 (see supporting information Table I which may be found in the online version of this article). All of the additional variants identified via oligo array in this sample were present in the database


C

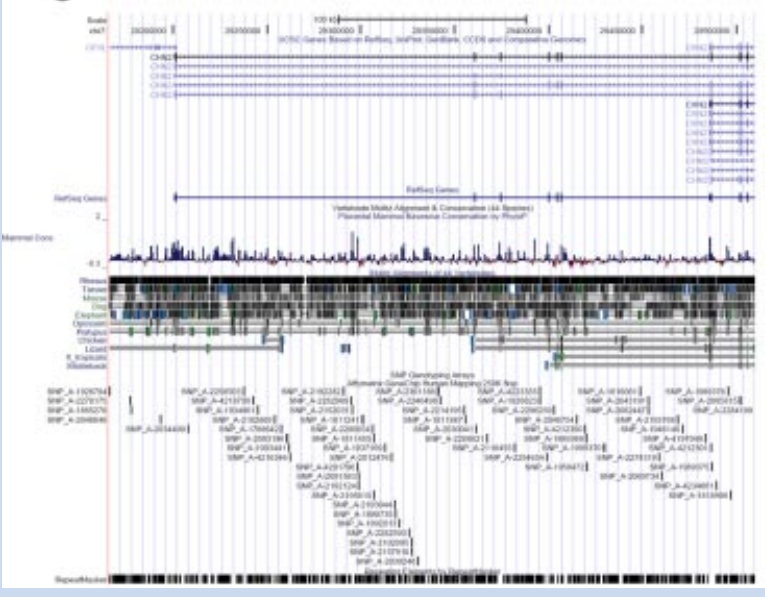

D

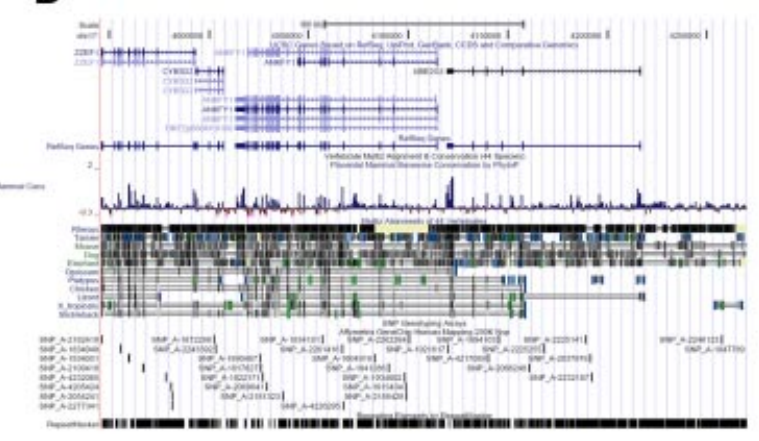

FIG. 1. Genomic duplications identified by SNP array. SNP data indicating the duplications carried by (A) Patient 1 on chromosome ?p15.1 and (B) Patient 9 on chromosome 17p13.2. The ideograms show the affected chromosome and banding patterns below the dosage of each SNP studied as indicated by red dots. The spike in the SNPs shows the duplications as indicated by an increase in the horizontal blue line and marked with an asterisk. The physical maps of the regions affected including the affected SNPs and genes are shown in (C) for Patient 1 and (D) for Patient 9 from the UCSC Genome Browser (http://www.genome.ucsc.edu). [Color figure can be viewed in the online issue, which is available at wileyonlinelibrary.com] 
of genomic variants, and thus are not likely causative of the OEIS/ EC phenotype.

Numerous CNVs were identified in the additional six patient samples (see supporting information Table I which may be found in the online version of this article). Patient 14 carries 23 changes, the highest number of identified changes within our cohort. In contrast, patient 11 carries 13 changes, the fewest we identified. We identified three CNVs each recurring in five different patient samples (see supporting information Table I which may be found in the online version of this article). These are well known copy number polymorphisms mapping to chromosomes 6p21.32 (HLA locus), 17q21.31 (also identified in our SNP array studies), and 22q11.23. In total our oligo array analysis identified an average of 19.2 changes per sample within our cohort. All of the changes identified via oligo array analysis were either present in the database of genomic variants or were deemed unlikely to be causative of the OEIS/EC phenotype based on the known or proposed function of the gene(s) therein and were not investigated further.

\section{TaqMan Assays}

TaqMan assays were performed in order to validate the novel DNA copy number changes identified by SNP chip analysis in Patients 1 and 9. The $344 \mathrm{~kb}$ pair duplication of chromosome 7p15.1 carried by Patient 1 was tested using a TaqMan assay mapping within intron 1 of the CHN2 gene with a standard RNase P assay as a copy number control. The probe location within intron one is roughly located in the middle of the duplicated DNA segment. The CHN2 TaqMan assay results confirmed the duplication identified in Patient 1 via SNP chip analysis. However, the assay also indicated that both parents are also heterozygous for this duplication and carry three copies of this locus (Fig. 2A).

A TaqMan assay located in the $3^{\prime}$ untranslated region of the ANKFY1 gene was used to verify the duplication of chromosome 17p13.2 identified by SNP chip analysis in Patient 9. The ANKYF1 TaqMan assay we performed is located roughly in the middle of the reported duplication. The assay when compared to the RNase $P$ control probe indicated that the patient carries three copies of this locus (Fig. 2B). Our results also indicated that the father is heterozygous for this duplication, and the mother is actually homozygous for the duplication (has four copies). Thus, it is unlikely that this duplication is causally related to the OEIS/EC phenotype.

As an additional validation of our array CGH results, we also ran assay Hs05018555_cn mapping to chromosome 7p21.3. This assay detects a deletion carried by Patient 11 that was found by both the SNP and oligo array. The deletion was confirmed in Patient 11 and we found it was inherited from the patient's father (data not shown).

\section{Candidate Gene Analysis}

A candidate gene approach was undertaken to determine possible single gene mutations causing the OIES/EC phenotype. We performed a thorough search of the published literature to identify genes that are known to play a role in caudal dysgenesis and/or urogenital malformations in both human and mouse models. This search revealed 14 candidate genes for analysis (Table III). Direct DNA sequencing of all the exons and exon/intron boundaries of these 14 candidate genes did not reveal any disease-causing mutations.

We identified a total of 48 different DNA changes in our analysis. Thirty eight of these changes were single nucleotide polymorphisms (SNPs) that are present in the database of SNPs (dbSNP) and as such were deemed not disease causing and were not tested for parental segregation (Table IV). We also identified 10 DNA changes that were novel and not present in dbSNP (Table V). Six of these novel changes mapped to intronic DNA, did not uncover a cryptic splice site, and were not investigated further. Within the $\mathrm{IHH}$ gene we identified a single $\mathrm{C}-\mathrm{T}$ transition within exon 3 in Patient 6 , which changes an arginine to a leucine. However, the mother of this patient carries the same DNA change.
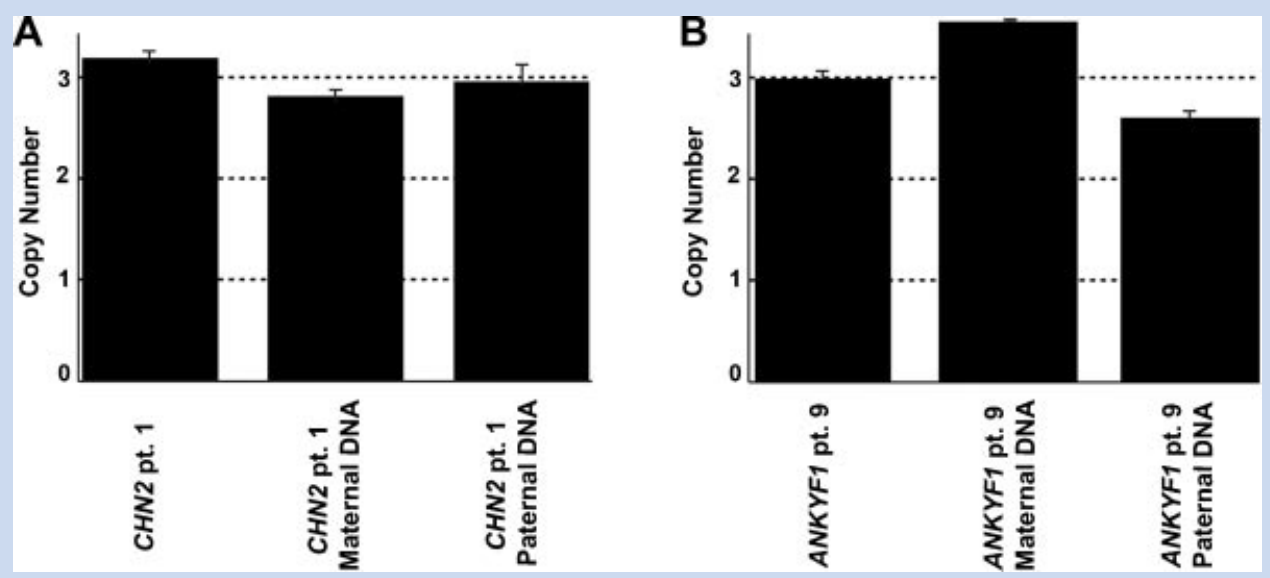

FIG. 2. Copy number analysis via TaqMan assay. (A) Assay Hs_04956436_en mapping to the CHN2 gene indicates a duplication carried by Patient 1 as well as both parents. (B) Assay Hs_0034272_cn mapping within the ANKFY1 gene on chromosome 17 indicates that Patient 9 and her father carry three copies of this locus, while her mother carries four copies. 


\begin{tabular}{|c|c|c|c|c|c|}
\hline Gene name & $\begin{array}{l}\text { GenBank } \\
\text { accession }\end{array}$ & $\begin{array}{l}\text { Chr. } \\
\text { Band }\end{array}$ & \# exons & Sequencing rationale & Refs. \\
\hline BMP4 & NM_130851 & $14 q 22.2$ & 4 & $\begin{array}{l}\text { Highly expressed in the tail bud, responsible for } \\
\text { differentiation in developing kidney in mouse }\end{array}$ & Brenner-Anantharam et al. [2007] \\
\hline CYP26A1 & NM_000783 & $10 q 23.33$ & 6 & $\begin{array}{l}\text { Knock-out mouse mutants die mid-gestation and } \\
\text { show tail truncation, fused kidneys, blind ending } \\
\text { hindgut, and abnormal urogenital sinus }\end{array}$ & Sakai et al. [2001] \\
\hline $\mathrm{DHH}$ & NM_021044 & $12 q 13.12$ & 3 & $\begin{array}{l}\text { DHH mutations in humans cause partial gonadal } \\
\text { dysgenesis. Dhh null mice are infertile and have } \\
\text { peripheral nerve abnormalities }\end{array}$ & $\begin{array}{l}\text { Bitgood et al. [1996], } \\
\text { Umehara et al. [2000] }\end{array}$ \\
\hline EFNB2 & NM_004093 & $13 q 33.3$ & 5 & $\begin{array}{l}\text { Efnb2 mutant mice display hypospadias, persitant } \\
\text { cloaca, and anorectal malformations }\end{array}$ & Dravis et al. [2004] \\
\hline FGF8 & NM_033164 & $10 q 24.32$ & 6 & $\begin{array}{l}\text { Fgf8 null mice fail to gastrulate and die } \sim \text { E10.5. } \\
\text { Highly expressed in the tail bud }\end{array}$ & $\begin{array}{l}\text { Crossley and Martin [1995], } \\
\text { Sun et al. [1999] }\end{array}$ \\
\hline $\mathrm{IHH}$ & NM_002181 & $2 q 35$ & 3 & $\begin{array}{l}\text { Ih mutant mice have malrotation, hypoplastic villi, } \\
\text { and Hirschsprung-like phenotype in colon. } / \mathrm{h} h / \mathrm{Sh} h \\
\text { double null mice have open gut }\end{array}$ & $\begin{array}{l}\text { Ramalho-Santos et al. [2000], } \\
\text { Zhang et al. [2001] }\end{array}$ \\
\hline p63 & NM_003722 & $3 q 28$ & 14 & $\begin{array}{l}\text { p63 null mice have bladder exstrophy. p63 mutations } \\
\text { in humans cause ectrodactyly, ectodermal dysplasia, } \\
\text { and facial clefts and other malformation syndromes }\end{array}$ & $\begin{array}{l}\text { Brunner et al. [2002], } \\
\text { Cheng et al. [2006] }\end{array}$ \\
\hline PCSK5 & NM_006200 & $9 q 21.13$ & 21 & $\begin{array}{l}\text { Mutation in mouse Pcsk } 5 \text { causes a VACTERL/caudal } \\
\text { regression phenotype }\end{array}$ & Szumska et al. [2008] \\
\hline $\mathrm{SHH}$ & NM_000193 & $7 q 36.3$ & 3 & $\begin{array}{l}\text { Mutations of Shh in mouse cause duodenal stenosis, } \\
\text { abnormal gut innervation, and imperforate anus. } \\
\text { Important for formation of cloaca and hindgut }\end{array}$ & $\begin{array}{l}\text { Haraguchi et al. [2007]; } \\
\text { Ramalho-Santos et al. [2000] }\end{array}$ \\
\hline$T$ & NM_003181 & $6 q 27$ & 8 & $\begin{array}{l}\text { Transcription factor required for proper mesoderm } \\
\text { formation. Classic mouse mutation affecting tail } \\
\text { length, sacral vertebrae, and the notochord }\end{array}$ & Herrmann et al. [1990] \\
\hline TBX6 & NM_004608 & $16 p 11.2$ & 8 & $\begin{array}{l}\text { Tbx6 null mouse embryos lack caudal somites and } \\
\text { form ectopic neural tubes }\end{array}$ & $\begin{array}{l}\text { Chapman and Papaioannou } \\
\text { [1998] }\end{array}$ \\
\hline WNT3 & NM_030753 & $17 q 21.32$ & 5 & $\begin{array}{l}\text { Wnt3 null mice fail to form primitive streak and } \\
\text { mesodermal tissue. Homozygous mutation of WNT3 } \\
\text { shown to cause tetra-amelia and urogenital } \\
\text { defects in a single family }\end{array}$ & $\begin{array}{l}\text { Liu et al. [1999], } \\
\text { Niemann et al. [2004] }\end{array}$ \\
\hline WNT3A & NM_033131 & $1 q 42.13$ & 4 & $\begin{array}{l}\text { Wnt3a null mice have complete absence of tailbud, } \\
\text { lack caudal somites, and have disrupted notochord; } \\
\text { vestigial tail mouse mutant a hypomorphic allele } \\
\text { of Wnt3a }\end{array}$ & $\begin{array}{l}\text { Greco et al. [1996], } \\
\text { Takada et al. [1994] }\end{array}$ \\
\hline WNTSB & NM_003396 & $17 q 21.32$ & 5 & $\begin{array}{l}\text { Regulates epithelial transition during urogenital } \\
\text { organogenesis }\end{array}$ & Carroll et al. [2005] \\
\hline
\end{tabular}

Two changes were found in the $5^{\prime}$ untranslated region of the WNT3 gene. In each case, the only parent available for analysis did not carry the change. Because only one parent was available we screened a panel of 100 DNA samples from apparently healthy individuals. The T-A transversion identified in Patient 14 was not found in 100 control samples, while the $\mathrm{C}-\mathrm{A}$ transversion identified in patient 15 was identified in 1 of the 100 control DNA samples screened and thus is likely a rare polymorphism.

In the FGF8 gene we identified an 18 bp duplication within exon 3 carried by Patient 9 . Since the duplication does not shift the frame, the additional bases result in the duplication of 6 amino acids in the protein. Segregation analysis revealed that the mother of Patient 9 also carries the duplication in FGF8. One hundred control individuals of a similar ethnic background (Northern European
Caucasian) were tested for this duplication, and none of the individuals carried the duplication. The six duplicated amino acids are not located in a conserved domain of the FGF8 protein.

A mutation in the $12 \mathrm{~S}$ ribosomal RNA gene located on the mitochondrial chromosome (MT-RNR1; GenBank Accession NC_012920 region 648-1,601) has previously been reported in the proband from a family exhibiting maternally inherited pigment anomalies and aminoglycoside-induced deafness [Nye et al., 2000]. In addition the proband also presented with myelocystocele-cloacal exstrophy. The mitochondrial A1555G mutation was found in the proband (exhibiting deafness and EC) as well as all deaf members of the pedigree. We tested all patients in our cohort for the mitochondrial A1555G mutation. None of the patients in our OEIS/EC cohort carried this mitochondrial mutation. 
TABLE IV. Known SNPs Identified During Candidate Gene Sequencing

\begin{tabular}{|c|c|c|c|c|c|c|}
\hline Gene & dbSNP accession & DNA change & AA change & Location & $\begin{array}{l}\text { No. pts. with } \\
\text { het. change }\end{array}$ & $\begin{array}{l}\text { No. pts. with } \\
\text { hom. change }\end{array}$ \\
\hline \multirow{2}{*}{ BMP4 } & rs2761880 & $A>G$ & $\mathrm{~N} / \mathrm{A}$ & Intron 3 & 0 & 13 \\
\hline & rs17563 & $T>C$ & $V>A$ & Exon 2 & 5 & 6 \\
\hline СYР26A1 & rs?4151825 & $A>G$ & N/A & Intron 2 & 1 & 0 \\
\hline EFNB2 & rs7995379 & $C>G$ & $G>G$ & Exon 5 & 0 & 13 \\
\hline \multirow{3}{*}{ IHH } & rs394452 & $G>A$ & $T>T$ & Exon 3 & 5 & $?$ \\
\hline & rs3731878 & $G>A$ & $T>T$ & Exon 3 & 1 & 0 \\
\hline & rs3731881 & $T>C$ & $P>P$ & Exon 3 & $?$ & 6 \\
\hline \multirow[t]{3}{*}{ P63 } & rs17514215 & $T>G$ & N/A & Intron 5 & 1 & 1 \\
\hline & rs33979049 & $C>T$ & $L>L$ & Exon 6 & 1 & 0 \\
\hline & rs679016? & $A>G$ & N/A & Intron 9 & 6 & 3 \\
\hline \multirow[t]{15}{*}{ PCSK5 } & rs?020560 & $G>A$ & $\mathrm{~L}>\mathrm{L}$ & Exon 1 & 1 & 0 \\
\hline & rs7040769 & $T>C$ & $c>c$ & Exon 1 & 3 & 0 \\
\hline & rs 4745472 & $G>A$ & N/A & Intron 1 & 0 & 1 \\
\hline & rs2297344 & $C>A$ & $\mathrm{~N} / \mathrm{A}$ & Intron? & 4 & 2 \\
\hline & rs141654? & $T>G$ & N/A & Intron 8 & 5 & 1 \\
\hline & rs2377429 & $T>C$ & N/A & Intron 8 & 6 & 0 \\
\hline & rs2297343 & $C>T$ & N/A & Intron 9 & 1 & 1 \\
\hline & rs41310061 & $G>A$ & $T>T$ & Exon 9 & 1 & 0 \\
\hline & rs3824474 & $A>G$ & $\mathrm{~N} / \mathrm{A}$ & Intron 11 & 1 & 0 \\
\hline & rs2297342 & $G>A$ & $S>S$ & Exon 12 & 2 & 2 \\
\hline & rs10124541 & $C>T$ & $P>P$ & Exon 14 & 1 & 0 \\
\hline & rs2270570 & $A>G$ & N/A & Intron 16 & 5 & 1 \\
\hline & rs1537183 & $G>A$ & N/A & Intron 16 & 0 & 13 \\
\hline & rs?046850 & $T>C$ & $\mathrm{~N} / \mathrm{A}$ & Intron 17 & 1 & 0 \\
\hline & rs10869726 & $G>A$ & N/A & Intron 20 & 2 & 0 \\
\hline \multirow[t]{2}{*}{ SHH } & rs1233554 & $T>G$ & $\mathrm{~N} / \mathrm{A}$ & Intron 3 & 6 & $?$ \\
\hline & rs1233555 & $G>A$ & N/A & Intron 2 & 9 & 4 \\
\hline \multirow[t]{5}{*}{$T$} & rs1056048 & $C>T$ & $S>S$ & Exon 3 & 2 & 2 \\
\hline & rs2305089 & $G>A$ & $G>D$ & Exon 4 & 4 & 5 \\
\hline & rs9459599 & $G>A$ & $\mathrm{~N} / \mathrm{A}$ & Intron 5 & 2 & 2 \\
\hline & rs3127328 & $G>A$ & $G>G$ & Exon 8 & 1 & 1 \\
\hline & rs35819705 & $G>A$ & $A>A$ & Exon 8 & 0 & 2 \\
\hline TBX6 & rs3809624 & $A>G$ & N/A & $3^{\prime}$ UTR & 2 & 0 \\
\hline \multirow[t]{5}{*}{ WNTGB } & rs4968281 & $T>C$ & $T>M$ & Exon 2 & 3 & 8 \\
\hline & rs11654422 & $G>A$ & N/A & Intron 2 & 4 & 3 \\
\hline & rs11654424 & $G>A$ & $\mathrm{~N} / \mathrm{A}$ & Intron 2 & 4 & 3 \\
\hline & rs34072914 & $G>T$ & $R>R$ & Exon 3 & 1 & 0 \\
\hline & rs754474 & $G>C$ & $V>V$ & Exon 4 & 2 & 0 \\
\hline
\end{tabular}

\section{DISCUSSION}

OEIS complex is a rare developmental field defect of unknown etiology. A significant genetic component is suspected based on the presence of familial cases and a higher concordance rate in monozygotic twins, yet no causative genes have been identified [Reutter et al., 2007b; Ludwig et al., 2009a]. The accumulating evidence for a strong genetic component as an underlying etiology for OEIS complex prompted us to perform a comprehensive genetic analysis of 13 individuals with OEIS complex. We sequenced 14 candidate genes and performed high resolution genomic arrays using either a $250 \mathrm{~K}$ SNP array or a $244 \mathrm{~K}$ oligonucleotide array. No causative mutations or genomic aberrations were identified in our patient cohort.
OEIS complex has been reported in association with Trisomy 21, Trisomy 18, Triple X syndrome, Turner mosaicism, and 1p36 deletion [Ludwig et al., 2009a; El-Hattab et al., 2010]. However, given the relatively high prevalence of these chromosomal disorders in the general population, it is unlikely that OEIS complex is causally associated with these chromosomal aberrations. Two patients with cloacal exstrophy and chromosomal deletions have been reported: one patient carrying an unbalanced translocation between chromosome 9 and the $\mathrm{Y}$ chromosome, resulting in monosomy for chromosome 9q34.1-qter, and one patient with $\operatorname{del}(3)(q 12.2 q 13.2)$ [Thauvin-Robinet et al., 2004; Kosaki et al., 2005]. One additional patient with OEIS complex and hypomelanosis of Ito has been reported [Leonard and Tomkins, 2002]. This patient was mosaic for a cell line with $\mathrm{t}(1 ; 6)(\mathrm{p} 32 ; \mathrm{q} 13)$ in fibroblasts. 
TABLE V. Novel SNPs Identified During Candidate Gene Sequencing

\begin{tabular}{|c|c|c|c|c|c|}
\hline Gene & Patient & DNA change & Amino acid change & Location & Nomenclature $^{a}$ \\
\hline \multirow[t]{2}{*}{ CYP26A1 } & 13 & $G>C$ & N/A & Intron 2 & IVS2 $+86 G>C$ \\
\hline & 15 & $G>C$ & N/A & Intron 2 & IVS2-99G $>C$ \\
\hline FGF8 & 9 & 18 bp duplication & 6 duplicated & Exon 3 & c.104_121dupAGCTCGCTTCCCTGTTCC \\
\hline \multirow[t]{2}{*}{$\mathrm{IHH}$} & 15 & $C>T$ & N/A & Intron 1 & $-\quad$ IVS1 $+49 C>T$ \\
\hline & 05 & $G>A$ & $R>L$ & Exon 3 & c. $1169 \mathrm{G}>\mathrm{A}$ \\
\hline PCSK5 & 05 & $T>A$ & $\mathrm{~N} / \mathrm{A}$ & Intron 16 & IVS16+58T $>A$ \\
\hline $\mathrm{SHH}$ & 14 & $C>T$ & N/A & Intron 3 & IVS3-7OC $>T$ \\
\hline \multirow[t]{2}{*}{ WNT3 } & 14 & $\mathrm{~T}>\mathrm{A}$ & N/A & $5^{\prime}$ UTR & c. $-73 \mathrm{~T}>\mathrm{A}$ \\
\hline & 15 & $C>A$ & N/A & $5^{\prime}$ UTR & c. $-86 C>A$ \\
\hline WNT9B & 9 & $T>C$ & N/A & Intron 2 & IVS2 $+86 \mathrm{~T}>C$ \\
\hline
\end{tabular}

${ }^{2}$ Nomenclature based on following accession numbers: CYP26A1:NM__000783, FGF8:NM_033163, IHH:NM_002181, PCKS5:NM_006200, WNT3:NM_030753, WNT9B:NM_003396.

A causal relationship between this translocation and OEIS complex is unclear. Chromosomal aberrations have also been reported in patients with BE and epispadias [Ludwig et al., 2009a]. However, no recurrent chromosomal aberrations have been identified either for OEIS complex or BE.

Several other studies examining candidate genes in patients with OEIS complex or BEEC have been performed. In general, these studies have examined one candidate gene in a small number of individuals. The homeobox gene HLXB9, which is mutated in Currarino syndrome (OMIM \#176450) [Ross et al., 1998], was sequenced in bladder DNA of five patients with OEIS/EC and leukocyte DNA from five patients with bladder exstrophy, and no mutations were identified [Boyadjiev et al., 2004]. Because of their respective genomic localizations near a reported translocation in a patient with OEIS complex, the NR5A1 (Steroidogenic factor-1) gene on 9q33.3 was analyzed in 1 patient with OEIS complex [Thauvin-Robinet et al., 2004], and the SET gene (Suppressor of variegation, Enhancer of Zeste and Trithorax) on 9q34.11 was analyzed in 33 patients with BEEC [Reutter et al., 2006]. No causative mutations were identified in either gene. Because of its localization at 9q13, which has been implicated in two independent translocations in BE, the CNTNAP3 gene was analyzed in several patients with BE, but no association was found [Boyadjiev et al., 2005]. The FGF10 gene was analyzed in 10 patients with OEIS because of its known role in urethral plate fusion based on mouse knockout models [Kruger et al., 2008]. Similarly, the TRP63 gene was analyzed based on the bladder exstrophy phenotype of the $\Delta$ Np63 knockout mouse [Cheng et al., 2006; Ching et al., 2007]. Again, no causative mutations were identified in either gene. In one patient with OEIS complex and aminoglycoside-induced sensorineural hearing loss, a mutation in the mitochondrial 12S RNA gene was identified [Nye et al., 2000]. However, the mutation in this family segregated with the hearing loss phenotype. Although other family members carrying the $12 \mathrm{~S}$ RNA mutation had minor urogenital anomalies, a causative relationship between the 12S RNA gene and OEIS complex could not be established. Furthermore, this mutation was not identified in any of the patients in our cohort.

The candidate genes in this study were chosen based on several different criteria. (1) Mouse knockout models with caudal or urogenital phenotypes, (2) a known role for the candidate gene in caudal and/or urogenital development in humans, or (3) embryonic expression patterns which suggest a potential role in caudal and/or urogenital development. We did not identify any point mutations that were unequivocally causative of the OEIS/EC phenotype. We did identify several known SNPs in our study, as well as a number of novel DNA changes. With the exception of variants in the $5^{\prime}$ untranslated region of the WNT3 gene in two patients, all of the other novel DNA changes were also carried by at least one unaffected parent. The novel variants identified in the WNT3 gene were not present in an unaffected parent, although only one parent was available for analysis. Although mutation of WNT3 has been associated with urogenital malformations and tetraamelia in one consanguineous family [Niemann et al., 2004], this recessive nonsense mutation likely led to loss of function of the gene, and the heterozygous carrier parents were normal. Intriguingly, the FGF8 duplication variant was not found in a control population of 100 individuals ( 200 chromosomes). Although singularly none of these changes are likely sufficient to cause OEIS/EC, we cannot rule out that they are associated with the disease phenotype. However, the rarity of this disorder limits our ability to obtain a sufficiently large patient cohort to perform the necessary statistical analysis to adequately test this hypothesis.

Only limited whole genome studies in patients with OEIS complex have been reported. One patient carrying a deletion of 3q12.2q13.2 was identified using bacterial artificial chromosome aCGH [Kosaki et al., 2005]. A copy number variant (CNV) was identified in a consanguineous family with three affected members with BE; however, this was a well known CNV on 1p21.1 encompassing the pancreatic and salivary amylase genes; thus it is unlikely related to the BE phenotype [Reutter et al., 2007a]. More recently, a genome-wide association study was performed in two BE families: one nonconsanguineous family with two affected family members and one consanguineous family with two affected family members [Ludwig et al., 2009b]. Although several genomic loci were identified with LOD scores of $>1.5$, a causative role for any of these regions remains to be established. Furthermore, these studies are based on an autosomal recessive mode of inheritance for BEEC, which has not definitively been established in the literature.

We utilized two different aCGH platforms in our study: a $250 \mathrm{~K}$ SNP array and a $244 \mathrm{~K}$ oligonucleotide array. We observed greater 
sensitivity with the oligonucleotide array. In the one sample that was analyzed on both platforms, the two CNVs that were identified by the SNP array were also identified by the oligo array, as well as 11 additional CNVs. However, higher density SNP arrays are now available that may improve the sensitivity of the SNP arrays. While we identified numerous CNVs in our patient cohort, the majority were known CNVs that are well represented in the database of genome variants. In addition, the only recurrent $\mathrm{CNVs}$ in our patient cohort are well known to be widely polymorphic. The CNVs that we identified that were not represented in the database of genome variants were both validated by TaqMan assay and were found to be present in at least one unaffected parent. Therefore, individually, none of the CNVs that we identified are likely to be causally associated with the OEIS complex phenotype. However, we cannot rule out the possibility that one or more of these CNVs may be a genetic risk factor for development of the OEIS complex phenotype in combination with other environmental or genetic risk factors [Klopocki et al., 2007]. Further, it is also possible that one of the CNVs could have unmasked a recessive mutation at one of these loci. Sequencing of the candidate genes contained within these CNVs in the other affected individuals could help to clarify this possibility.

Based on our current knowledge of OEIS complex, the majority of individuals represent sporadic cases, and the recurrence risk for future pregnancies is thought to be low. Although other modes of inheritance cannot be completely excluded, this is most consistent with a de novo mutation in a gene that affects development of caudal and urogenital structures. Because so few affected individuals reproduce, it is difficult to know whether these affected individuals would pass along the complete OEIS complex phenotype to their offspring. For the few familial cases, the inheritance pattern has been most consistent with autosomal dominant inheritance with reduced penetrance and/or variable expressivity, influenced either by other genetic or epigenetic factors [Keppler-Noreuil, 2001; Boyadjiev et al., 2004]. Recently, it has been proposed that the Disorganization gene $(D s)$ in mice may represent a model for OEIS complex including limb malformations in humans [Robin et al., 2007]. Ds mice have variable phenotypes that can resemble OEIS complex, and the penetrance is known to be low. However, since the $D s$ gene has not yet been identified, it is impossible to prove or disprove this interesting theory.

At this time, the pathogenesis of OEIS complex remains elusive. The lack of a single genetic etiology precludes the creation of an animal model, and the lack of an animal model that completely recapitulates the phenotype limits the ability to study developmental pathways and isolate candidate genes. It is most likely that OEIS complex is a developmental field defect of the cells comprising the caudal eminence, and perturbation of this region at specific time points during development, either by genetic or environmental factors, leads to the OEIS complex phenotype.

While no causative genetic explanation was found in this study, it is still likely that there are as of yet unidentified genes that strongly contribute to the OEIS complex phenotype, and additional research is needed. Although a large number of candidate genes were analyzed in this study, we cannot rule out that a mutation in one of these genes could cause an OEIS complex phenotype in rare patients, or that some of the rare variants that were found are associated with the disease phenotype and have reduced penetrance in unaffected parents. While we did not identify any unique recurrent CNV that might contain a candidate gene for OEIS complex, we also cannot exclude the possibility that rare CNVs might cause OEIS complex. However, it is unlikely that OEIS complex is caused by a recurrent genomic $\mathrm{CNV}$.

\section{ACKNOWLEDGMENTS}

The authors would like to thank the patients and their families for their participation in this study. We also thank the referring physicians and genetic counselors for kindly providing patient samples and clinical information and Dr. Jeffrey Innis for critically reviewing this manuscript. We acknowledge the DNA sequencing Core of the University of Michigan's Biomedical Research Core Facilities. Core support was provided by the University of Michigan Comprehensive Cancer Center (CA46592) and the Michigan Diabetes Research and Training Center (NIH5P60-DK20572). This work was supported by the Department of Pediatrics AmendtHeller award for newborn research and a Rackham faculty research grant to CEK. CNV was supported by a postdoctoral fellowship from the Center for Genetics in Health and Medicine at the University of Michigan.

\section{REFERENCES}

Baldwin EL, Lee JY, Blake DM, Bunke BP, Alexander CR, Kogan AL, Ledbetter DH, Martin CL. 2008. Enhanced detection of clinically relevant genomic imbalances using a targeted plus whole genome oligonucleotide microarray. Genet Med 10:415-429.

Bitgood MJ, Shen L, McMahon AP. 1996. Sertoli cell signaling by Desert hedgehog regulates the male germline. Curr Biol 6:298-304.

Bohring A. 2002. OEIS complex, VATER, and the ongoing difficulties in terminology and delineation. Am J Med Genet 107:72-76.

Boyadjiev SA, Dodson JL, Radford CL, Ashrafi GH, Beaty TH, Mathews RI, Broman KW, Gearhart JP. 2004. Clinical and molecular characterization of the bladder exstrophy-epispadias complex: Analysis of 232 families. $\mathrm{Br}$ J Urol Int 94:1337-1343.

Boyadjiev SA, South ST, Radford CL, Patel A, Zhang G, Hur DJ, Thomas GH, Gearhart JP, Stetten G. 2005. A reciprocal translocation $46, \mathrm{XY}, \mathrm{t}(8 ; 9)(\mathrm{p} 11.2 ; \mathrm{q} 13)$ in a bladder exstrophy patient disrupts CNTNAP3 and presents evidence of a pericentromeric duplication on chromosome 9. Genomics 85:622-629.

Brenner-Anantharam A, Cebrian C, Guillaume R, Hurtado R, Sun TT, Herzlinger D. 2007. Tailbud-derived mesenchyme promotes urinary tract segmentation via BMP4 signaling. Development 134:1967-1975.

Brunner HG, Hamel BC, Bokhoven Hv H. 2002. P63 gene mutations and human developmental syndromes. Am J Med Genet 112:284-290.

Carey JC, Greenbaum B, Hall BD. 1978. The OEIS complex (omphalocele, exstrophy, imperforate anus, spinal defects). Birth Defects Orig Artic Ser 14:253-263.

Carroll TJ, Park JS, Hayashi S, Majumdar A, McMahon AP. 2005. Wnt9b plays a central role in the regulation of mesenchymal to epithelial transitions underlying organogenesis of the mammalian urogenital system. Dev Cell 9:283-292.

Chapman DL, Papaioannou VE. 1998. Three neural tubes in mouse embryos with mutations in the T-box gene Tbx6. Nature 391:695-697. 
Cheng W, Jacobs WB, Zhang JJ, Moro A, Park JH, Kushida M, Qiu W, Mills AA, Kim PC. 2006. \{Delta\}Np63 plays an anti-apoptotic role in ventral bladder development. Development 133:4783-4792.

Ching BJ, Ludwig M, Reutter H, Nauta C, Gearhart JP, Boyadjiev SA. 2007. Potential role of $\mathrm{p} 63$ in human bladder exstrophy. 57th Annual meeting of The American Society of Human Genetics:p.478 (abstr).

Crossley PH, Martin GR. 1995. The mouse Fgf8 gene encodes a family of polypeptides and is expressed in regions that direct outgrowth and patterning in the developing embryo. Development 121:439-451.

Dravis C, Yokoyama N, Chumley MJ, Cowan CA, Silvany RE, Shay J, Baker LA, Henkemeyer M. 2004. Bidirectional signaling mediated by ephrin-B2 and EphB2 controls urorectal development. Dev Biol 271:272-290.

El-Hattab AW, Skorupski JC, Hsieh MH, Breman AM, Patel A, Cheung SW, Craigen WJ. 2010. OEIS complex associated with chromosome 1p36 deletion: A case report and review. Am J Med Genet Part A 152A: 504-511.

Greco TL, Takada S, Newhouse MM, McMahon JA, McMahon AP, Camper SA. 1996. Analysis of the vestigial tail mutation demonstrates that Wnt-3a gene dosage regulates mouse axial development. Genes Dev 10:313-324.

Haraguchi R, Motoyama J, Sasaki H, Satoh Y, Miyagawa S, Nakagata N, Moon A, Yamada G. 2007. Molecular analysis of coordinated bladder and urogenital organ formation by Hedgehog signaling. Development 134:525-533.

Herrmann BG, Labeit S, Poustka A, King TR, Lehrach H. 1990. Cloning of the $\mathrm{T}$ gene required in mesoderm formation in the mouse. Nature 343: 617-622.

Heyroth-Griffis CA, Weaver DD, Faught P, Bellus GA, Torres-Martinez W. 2007. On the spectrum of limb-body wall complex, exstrophy of the cloaca, and urorectal septum malformation sequence. Am J Med Genet Part A 143A:1025-1031.

Jones KL. 1997. Smith's recognizable patterns of human malformation. Philadelphia: W.B. Saunders Company.

Kallen K, Castilla EE, Robert E, Mastroiacovo P, Kallen B. 2000. OEIS complex-A population study. Am J Med Genet 92:62-68.

Keppler-Noreuil KM. 2001. OEIS complex (omphalocele-exstrophyimperforate anus-spinal defects): A review of 14 cases. Am J Med Genet 99:271-279.

Keppler-Noreuil K, Gorton S, Foo F, Yankowitz J, Keegan C. 2007. Prenatal ascertainment of OEIS complex/cloacal exstrophy-15 new cases and literature review. Am J Med Genet Part A 143A:2122-2128.

Klopocki E, Schulze H, Strauss G, Ott CE, Hall J, Trotier F, Fleischhauer S, Greenhalgh L, Newbury-Ecob RA, Neumann LM, Habenicht R, Konig R, Seemanova E, Megarbane A, Ropers HH, Ullmann R, Horn D, Mundlos S. 2007. Complex inheritance pattern resembling autosomal recessive inheritance involving a microdeletion in thrombocytopenia-absent radius syndrome. Am J Hum Genet 80:232-240.

Koolen DA, Vissers LE, Pfundt R, de Leeuw N, Knight SJ, Regan R, Kooy RF, Reyniers E, Romano C, Fichera M, Schinzel A, Baumer A, Anderlid BM, Schoumans J, Knoers NV, van Kessel AG, Sistermans EA, Veltman JA, Brunner HG, de Vries BB. 2006. A new chromosome 17q21.31 microdeletion syndrome associated with a common inversion polymorphism. Nat Genet 38:999-1001.

Kosaki R, Fukuhara Y, Kosuga M, Okuyama T, Kawashima N, Honna T, Ueoka K, Kosaki K. 2005. OEIS complex with del(3)(q12.2q13.2). Am J Med Genet Part A 135A:224-226.

Kruger V, Khoshvaghti M, Reutter H, Vogt H, Boemers TM, Ludwig M. 2008. Investigation of FGF10 as a candidate gene in patients with anorectal malformations and exstrophy of the cloaca. Pediatr Surg Int 24:893-897.
Lee DH, Cottrell JR, Sanders RC, Meyers CM, Wulfsberg EA, Sun CC. 1999. OEIS complex (omphalocele-exstrophy-imperforate anus-spinal defects) in monozygotic twins. Am J Med Genet 84:29-33.

Leonard NJ, Tomkins DJ. 2002. Diploid/tetraploid/t(1;6) mosaicism in a 17 -year-old female with hypomelanosis of Ito, multiple congenital anomalies, and body asymmetry. Am J Med Genet 112:86-90.

Liu P, Wakamiya M, Shea MJ, Albrecht U, Behringer RR, Bradley A. 1999. Requirement for Wnt3 in vertebrate axis formation. Nat Genet 22: 361-365.

Ludwig M, Ching B, Reutter H, Boyadjiev SA. 2009a. Bladder exstrophyepispadias complex. Birth Defects Res A Clin Mol Teratol 85:509-522.

Ludwig M, Ruschendorf F, Saar K, Hubner N, Siekmann L, Boyadjiev SA, Reutter H. 2009b. Genome-wide linkage scan for bladder exstrophyepispadias complex. Birth Defects Res A Clin Mol Teratol 85:174-178.

Martinez-Frias ML, Bermejo E, Rodriguez-Pinilla E, Frias JL. 2001. Exstrophy of the cloaca and exstrophy of the bladder: Two different expressions of a primary developmental field defect. Am J Med Genet 99:261-269.

Nannya Y, Sanada M, Nakazaki K, Hosoya N, Wang L, Hangaishi A, Kurokawa M, Chiba S, Bailey DK, Kennedy GC, Ogawa S. 2005. A robust algorithm for copy number detection using high-density oligonucleotide single nucleotide polymorphism genotyping arrays. Cancer Res 65: 6071-6079.

Niemann S, Zhao C, Pascu F, Stahl U, Aulepp U, Niswander L, Weber JL, Muller U. 2004. Homozygous WNT3 mutation causes tetra-amelia in a large consanguineous family. Am J Hum Genet 74:558-563.

Nye JS, Hayes EA, Amendola M, Vaughn D, Charrow J, McLone DG, Speer MC, Nance WE, Pandya A. 2000. Myelocystocele-cloacal exstrophy in a pedigree with a mitochondrial $12 \mathrm{~S}$ rRNA mutation, aminoglycosideinduced deafness, pigmentary disturbances, and spinal anomalies. Teratology 61:165-171.

Ramalho-Santos M, Melton DA, McMahon AP. 2000. Hedgehog signals regulate multiple aspects of gastrointestinal development. Development 127:2763-2772.

Reutter H, Thauvin-Robinet C, Boemers TM, Rosch WH, Ludwig M. 2006. Bladder exstrophy-epispadias complex: Investigation of suppressor of variegation, enhancer of zeste and Trithorax (SET) as a candidate gene in a large cohort of patients. Scand J Urol Nephrol 40:221-224.

Reutter H, Hoischen A, Ludwig M, Stein R, Radlwimmer B, Engels H, Wolffenbuttel KP, Weber RG. 2007a. Genome-wide analysis for microaberrations in familial exstrophy of the bladder using array-based comparative genomic hybridization. Br J Urol Int 100:646-650.

Reutter H, Qi L, Gearhart JP, Boemers T, Ebert AK, Rosch W, Ludwig M, Boyadjiev SA. 2007b. Concordance analyses of twins with bladder exstrophy-epispadias complex suggest genetic etiology. Am J Med Genet Part A 143A:2751-2756.

Robin NH, Sathienkijkanchai A, Herndon CD. 2007. A genetic model for cloacal exstrophy, the extreme cloacal malformation. J Pediatr Urol 3: 214-217.

Ross AJ, Ruiz-Perez V, Wang Y, Hagan DM, Scherer S, Lynch SA, Lindsay S, Custard E, Belloni E, Wilson DI, Wadey R, Goodman F, Orstavik KH, Monclair T, Robson S, Reardon W, Burn J, Scambler P, Strachan T. 1998. A homeobox gene, HLXB9, is the major locus for dominantly inherited sacral agenesis. Nat Genet 20:358-361.

Sadler TW, Feldkamp ML. 2008. The embryology of body wall closure: Relevance to gastroschisis and other ventral body wall defects. Am J Med Genet Part C 148C:180-185.

Sakai Y, Meno C, Fujii H, Nishino J, Shiratori H, Saijoh Y, Rossant J, Hamada H. 2001. The retinoic acid-inactivating enzyme CYP26 is essential for establishing an uneven distribution of retinoic acid along 
the anterioposterior axis within the mouse embryo. Genes Dev 15: 213-225.

Siebert JR, Rutledge JC, Kapur RP. 2005. Association of cloacal anomalies, caudal duplication, and twinning. Pediatr Dev Pathol 8:339-354.

Sun X, Meyers EN, Lewandoski M, Martin CR. 1999. Targeted disruption of Fgf8 causes failure of cell migration in the gastrulating mouse embryo. Genes Dev 13:1834-1846.

Szumska D, Pieles G, Essalmani R, Bilski M, Mesnard D, Kaur K, Franklyn A, El Oman, Jefferis K, Bentham J, Taylor JM, Schneider JE, Arnold SJ, Johnson P, Tymowska-Lalanne Z, Stammers D, Clarke K, Neubauer S, Morris A, Brown SD, Shaw-Smith C, Cama A, Capra V, Ragoussis J, Constam D, Seidah NC, Prat A, Bhattacharya S. 2008. VACTERL/caudal regression/Curranino syndrome-like malformations in mice with mutation in the proprotein convertase Pcsk5. Genes Dev 22:14651477.
Takada S, Stark KL, Shea MJ, Vassileva C, McMahon JA, McMahon AR. 1994. Wnt-3a regulates somite and tailbud formation in the mouse embryo. Genes Dev 8:174-189.

Thauvin-Robinet C, Faivre L, Cusin V, Khau Van Kien P, Callier P, Parker KL, Fellous M, Borgnon J, Gounot E, Huet F, Sapin E, Mugneret F. 2004. Cloacal exstrophy in an infant with 9q34.1-qter deletion resulting from a de novo unbalanced translocation between chromosome $9 \mathrm{q}$ and Yq. Am J Med Genet Part A 126A:303-307.

Umehara F, Tate G, Itoh K, Yamaguchi N, Douchi T, Mitsuya T, Osame M. 2000. A novel mutation of desert hedgehog in a patient with 46 ,XY partial gonadal dysgenesis accompanied by minifascicular neuropathy. Am J Hum Genet 67:1302-1305.

Zhang XM, Ramaiho-Santos M, McMahon AP. 2001. Smoothened mutants reveal redundant roles for Shh and lhh signaling including regulation of L/R symmetry by the mouse node. Cell 106:781-792. 